\title{
Isolation and Identification of $\alpha$-CEHC Sulfate in Rat Urine and an Improved Method for the Determination of Conjugated $\alpha$-CEHC
}

\author{
YI-Jen Li,${ }^{\dagger}$ Sheng-Ching Luo, ${ }^{\dagger}$ Yi-Jing LeE, ${ }^{\dagger}$ Fu-Jung Lin, ${ }^{\dagger}$ \\ Chi-Cheng Cheng, ${ }^{\dagger}$ Yung-Shung Wein, ${ }^{\ddagger}$ Yueh-Hsiung Kuo, ${ }^{\ddagger},{ }^{\prime \prime l, \perp}$ And \\ CHING-JANG HUANG ${ }^{*}, \dagger, \#$ \\ Division of Nutritional Biochemistry, Institute of Microbiology and Biochemistry, National Taiwan \\ University, 1, Sec. 4, Roosevelt Rd., Taipei, 106, Taiwan, Department of Chemistry, National Taiwan \\ University, Taipei, Taiwan, Department of Biochemical Science and Technology, National \\ Taiwan University, Taipei, Taiwan, College of Pharmacy, China Medical University, Taichung, 404, \\ Taiwan, and Agricultural Biotechnology Research Center, Academia Sinica, Taipei, 115, Taiwan
}

\begin{abstract}
2,5,7,8-Tetramethyl-2-(2'-carboxyethyl)-6-hydroxychroman ( $\alpha$-CEHC), the water-soluble metabolite of $\alpha$-tocopherol $(\alpha-\mathrm{TOH})$ with a shortened side chain but an intact hydroxychroman structure, has been identified in human urine and are thought to be produced in significant amount at excess intake of $\alpha-\mathrm{TOH}$. In previous studies, CEHCs in biological specimens were measured by HPLC, GC-MS or LC-MS, preceded by a hydrolysis procedure using either enzyme or methanolic $\mathrm{HCl}$. In an attempt to analyze $\alpha-C E H C$ in rat urine accordingly, we observed that enzyme hydrolysis was relatively inefficient in releasing $\alpha-\mathrm{CEHC}$ compared to high concentrations of $\mathrm{HCl}$. The $\mathrm{HCl}$ releasable $\alpha-\mathrm{CEHC}$ conjugate was isolated and chemically identified as $6-O$-sulfated $\alpha$-CEHC ( $\alpha$-CEHC sulfate). Using the synthetic $\alpha-C E H C$ sulfate standard, it was found that sulfatase could not hydrolyze to a significant extent. On the other hand, pretreatment with $\mathrm{HCl}$ at $60^{\circ} \mathrm{C}$ in the presence of ascorbate, followed by a one-step ether extraction, not only hydrolyzed the sulfate conjugate completely but also extracted $\alpha$-CEHC with high recovery. The inclusion of ascorbate minimized the conversion of $\alpha-C E H C$ to $\alpha$-tocopheronolactone in the $\mathrm{HCl}$ pretreatment. A complete procedure for the quantitative analysis of $\alpha-\mathrm{CEHC}$ including $\mathrm{HCl}$ hydrolysis, ether extraction and reverse phase isocratic HPLC-ECD was thus established. In conclusion, $\alpha-\mathrm{CEHC}$ sulfate was isolated and identified as the $\mathrm{HCl}$-releasable conjugate of $\alpha-\mathrm{CEHC}$ in rat urine. A rapid and sensitive method with high reproducibility for the determination of free, conjugated and total $\alpha-\mathrm{CEHC}$ is then established.
\end{abstract}

KEYWORDS: Vitamin E metabolism; $\alpha$-TOH; $\alpha$-CEHC; sulfate conjugate; HPLC-ECD

\section{INTRODUCTION}

Vitamin E, and in particular $\alpha$-tocopherol $(\alpha-\mathrm{TOH})($ Figure $\mathbf{1}$ ), is the major fat soluble antioxidant in the body, protecting cellular membranes and other lipids against oxidative damage caused by oxygen-derived free radicals (1). $\alpha$-TOH is the most abundant form in the body accounting for over $90 \%$ of the total vitamin E retained, even though $\gamma$-tocopherol is generally the most abundant form in the diet (2). For a long time, catabolism

* Corresponding author. Tel: +886-2-33662276. Fax: +886-223621301. E-mail: cjjhuang@ntu.edu.tw.

${ }^{\dagger}$ Institute of Microbiology and Biochemistry, National Taiwan University.

¥Department of Chemistry, National Taiwan University.

${ }^{\S}$ Equal contribution with corresponding author.

"China Medical University.

${ }^{\perp}$ Academia Sinica.

\# Department of Biochemical Science and Technology, National Taiwan University. of $\alpha-\mathrm{TOH}$ was thought to start with a radical attack on the chroman structure resulting in the formation of $\alpha$-tocopherylquinone. The subsequent side chain degradation then leads to final products, $\alpha$-tocopheronic acid and the lactone derived therefrom (the so-called Simon's metabolites), that are excreted in urine (3). More than a decade ago, 2,5,7,8-tetramethyl-2-(2'-carboxyethyl)-6-hydroxychroman ( $\alpha$-CEHC), the water-soluble metabolite of $\alpha-\mathrm{TOH}$ with a shortened side chain but an intact hydroxychroman structure, has been discovered in human urine. Its chroman ring is intact, indicating that the vitamin has not been subjected to the presumed radical scavenging reaction in this metabolic pathway. Furthermore, this metabolite is reported to be produced in significant amount at excess intake of $\alpha$-TOH (4).

To date, most vitamin $\mathrm{E}$ isoforms are shown to be catabolized to the corresponding CEHC (4-7). These CEHCs in biological specimens have been measured by GC-MS (4), LC-MS (8), 
$\operatorname{HPLC}-\operatorname{ECD}(9,10)$ or $\operatorname{HPLC}-$ fluorescence $(11,12)$ with a prior hydrolysis and extraction process. The hydrolysis step used either acid methylation or enzyme hydrolysis to yield either the methyl ester $(10)$ or free metabolite $(4,9)$. Acid hydrolysis in aqueous phase has rarely been employed since Schultz et al. (4) demonstrated that $\alpha$-tocopheronolactone could be artificially formed from $\alpha$-CEHC during sample handling, while Pope et al. (13) showed evidence of possible in vivo formation of $\alpha$-tocopheronolactone. Acid methylation, on the other hand, can protect $\alpha$-CEHC from conversion to $\alpha$-tocopheronolactone (10).

There is disagreement as to whether the CEHCs are excreted as glucuronides or sulfates even though $\beta$-glucuronidase is the enzyme most commonly used for the hydrolysis of the conjugates (14-17). Schultz et al. (4) could not obtain free $\alpha$-CEHC while hydrolyzing human urine with pure glucuronidase (without sulfatase activity) at $\mathrm{pH} 4.5$. They concluded that $\alpha$-CEHC sulfate but not glucuronide was the predominant conjugate present in human urine. Tanabe et al. (18) observed that when $\gamma$-CEHC was administered to rats, it was excreted into urine as $6-O$-sulfated $\gamma$-CEHC identified by using an HPLC tandem mass spectrometry (MS-MS). On the other hand, the procedure of Morinobu et al. (19) used $\beta$-glucuronidase without sulfatase activity since no difference in the amount of CEHC was detected between using the enzyme with and without sulfatase activity. They thus suggested that the $\alpha$-CEHC in human urine is predominantly glucuronide conjugate. Using synthetic $\alpha$-CEHC glucuronide and $\alpha$-CEHC sulfate standards, Pope et al. (20) were able to detect these conjugates directly (without prior hydrolysis) in human urine by tandem mass spectrometry (ESI-MS-MS). Peaks with $\mathrm{m} / \mathrm{z}$ of 453 and 357 were respectively designated as glucuronide and sulfate conjugates of $\alpha$-CEHC or $\alpha$-tocopheronolactone. However, they found a comparable collision induced dissociation (CID) spectrum of urine extract to standard compound for $\alpha$-CEHC glucuronide, but not for $\alpha$-CEHC sulfate, presumably because of the relatively small amount. The controversy indicates that the method for the determination of conjugated $\alpha$-CEHC needs further investigation.

In an attempt to measure $\alpha$-CEHC in rat urine according to reported methods $(7,9)$, we observed that $\beta$-glucuronidase with sulfatase activity only released a very small amount of $\alpha$-CEHC whereas $\mathrm{HCl}$ treatment resulted in extremely high amount. In the present study, therefore, we first isolated and identified $\alpha$-CEHC sulfate as the $\mathrm{HCl}$ releasable conjugate in rat urine. Using the synthetic $\alpha$-CEHC sulfate standard, the acid hydrolysis condition was optimized to achieve complete hydrolysis with minimal conversion of $\alpha$-tocopheronolactone. A rapid and sensitive method with high reproducibility for the determination of free, conjugated and total $\alpha$-CEHC by isocratic HPLC was thus established.

\section{MATERIALS AND METHODS}

Chemicals and Reagents. $\alpha$-CEHC, $\alpha$-tocopheronolactone and $\alpha$-CEHC sulfate were synthesized by a procedure similar to that reported by Pope et al. (20). The details are described in Supporting Information (Schemes $\mathrm{S} 1-\mathrm{S} 3$ ). $\beta$-Glucuronidase (type $\mathrm{H}-1$, contains minimum $300,000 \mathrm{U} / \mathrm{g} \beta$-glucuronidase activity and minimum 10,000 U/g sulfatase activity) and sulfatase (Type H-1, contains minimum 10,000 U/g sulfatase activity) were purchased from Sigma Chemical Co. All remaining chemicals and reagents were of the highest purity available or HPLC-grade.

Urine Sample Preparation. Rat urine was obtained from normal Wistar rats (purchased from the Laboratory Animal center of College of Medicine, National Taiwan University (NTU)) fed modified AIN76 diets containing 50 or $500 \mathrm{mg} / \mathrm{kg}$ all-rac- $\alpha$-tocopheryl acetate. The

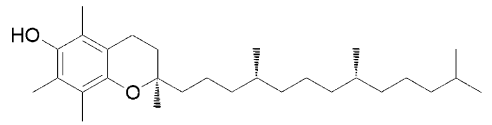

(A) $\alpha$-Tocopherol

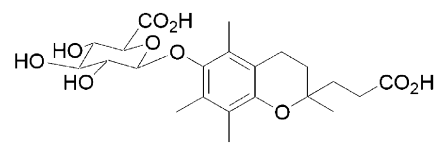

(C) $\alpha$-CEHC glucuronide

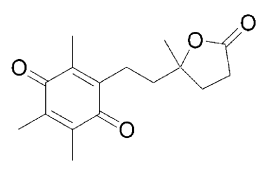

(E) $\alpha$-Tocopheronolactone (benzoquinone)

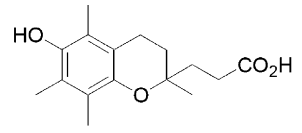

(B) $\alpha-\mathrm{CEHC}$

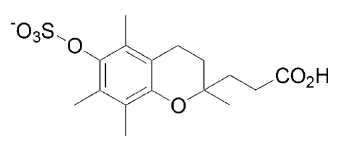

(D) $\alpha$-CEHC sulfate

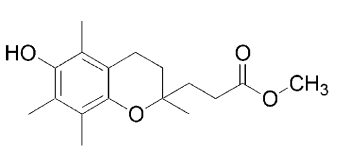

(F) $\alpha$-CEHC-Me
Figure 1. The chemical structure of $\alpha$-tocopherol, $\alpha-\mathrm{CEHC}$ and its associated compounds. (A) $\alpha$-tocopherol, (B) $\alpha$-CEHC, (C) $\alpha$-CEHC glucuronide, (D) $\alpha$-CEHC sulfate, (E) $\alpha$-tocopheronolactone (benzoquinone) and (F) $\alpha$-CEHC-Me.

experiment was carried out under the guidelines of the care and use of laboratory animal committee of NTU. Rats were individually housed in metabolic cages, and urine was collected into the collection tube on ice. All urine samples were stored in $-20{ }^{\circ} \mathrm{C}$ under $\mathrm{N}_{2}$ before the analysis.

Hydrolysis of $\alpha$-CEHC Conjugates. Tested samples (rat urine or standard compound solutions) contained $20 \mathrm{mg} / \mathrm{mL}$ of ascorbate except for those that were tested for the protection of ascorbate. For the analysis of free $\alpha$-CEHC in the rat urine, samples were adjusted to $\mathrm{pH} 4$ by adding ascorbate and extracted by diethyl ether directly without prior enzyme or $\mathrm{HCl}$ hydrolysis.

$\boldsymbol{\beta}$-Glucuronidase and Sulfatase Hydrolysis. The procedures were modified from those reported previously $(7,9)$. Prior to extraction, 1 $\mathrm{mL}$ tested samples were hydrolyzed by adding $200 \mu \mathrm{L}$ of enzyme solution (1000 $\mathrm{U}$ of $\beta$-glucuronidase or $50 \mathrm{U}$ of sulfatase in $0.1 \mathrm{M}$ sodium acetate buffer, $\mathrm{pH} 4.5$ ) and incubated for 16 or $2 \mathrm{~h}$ respectively at $37^{\circ} \mathrm{C}$. After cooling on ice, the samples were extracted with diethyl ether by mixing thoroughly and the mixtures were centrifuged at 2000 rpm for $5 \mathrm{~min}$ to separate the layers. An aliquot of the ether layer was dried under vacuum, and the residue was reconstituted in mobile phase for being analyzed using HPLC (see below). To validate the hydrolysis procedure, samples were also incubated with various amounts of enzyme.

HCl Hydrolysis. 0 to $12 \mathrm{~N} \mathrm{HCl}(1 \mathrm{~mL})$ was added to $1 \mathrm{~mL}$ tested sample for acid hydrolysis with or without incubating in a $60^{\circ} \mathrm{C}$ water bath for $1 \mathrm{~h}$ under $\mathrm{N}_{2}$, extracted with diethyl ether and then analyzed by HPLC as described above. The $\alpha$-tocopheronolactone was also extracted together with $\alpha$-CEHC on this procedure.

Acid Methylation/Hydrolysis. The conjugated $\alpha$-CEHC was hydrolyzed by acid methylation according to the method of Kiyose et al. (10). The tested sample ( $1 \mathrm{~mL}$, containing $20 \mathrm{mg}$ ascorbate) was lyophilized and added with $2 \mathrm{~mL}$ of 3 or $6 \mathrm{~N}$ methanolic $\mathrm{HCl}$, shaking at $60{ }^{\circ} \mathrm{C}$ for $1 \mathrm{~h}$ under $\mathrm{N}_{2}$. After methylation, samples were cooled on ice, $6 \mathrm{~mL}$ of water was then added to each sample and extracted with $8 \mathrm{~mL}$ of $n$-hexane by shaking vigorously for $1 \mathrm{~min}$. This mixture was centrifuged at $3000 \mathrm{rpm}$ for $5 \mathrm{~min}$, and the upper layer was collected and evaporated. The residue was dissolved in mobile phase which was composed of acetonitrile $\left(\mathrm{CH}_{3} \mathrm{CN}\right) / \mathrm{H}_{2} \mathrm{O}(43: 57$, v/v) containing $50 \mathrm{mM}$ ammonium acetate $(\mathrm{pH} 4.5)$ for HPLC analysis.

HPLC Analysis. For the analysis of $\alpha$-CEHC and methyl esters of $\alpha$-CEHC ( $\alpha$-CEHC-Me), the detector used was a EAS coulochem II $5200 \mathrm{~A}$ electrochemical detector. For the analysis of $\alpha$-tocopheronolactone, a Jasco $870-\mathrm{UV} / \mathrm{vis}$ detector $(870-\mathrm{UV})$ was used. The peaks were identified by the standard compound, and concentrations of samples were calculated according to the external standard mode. 


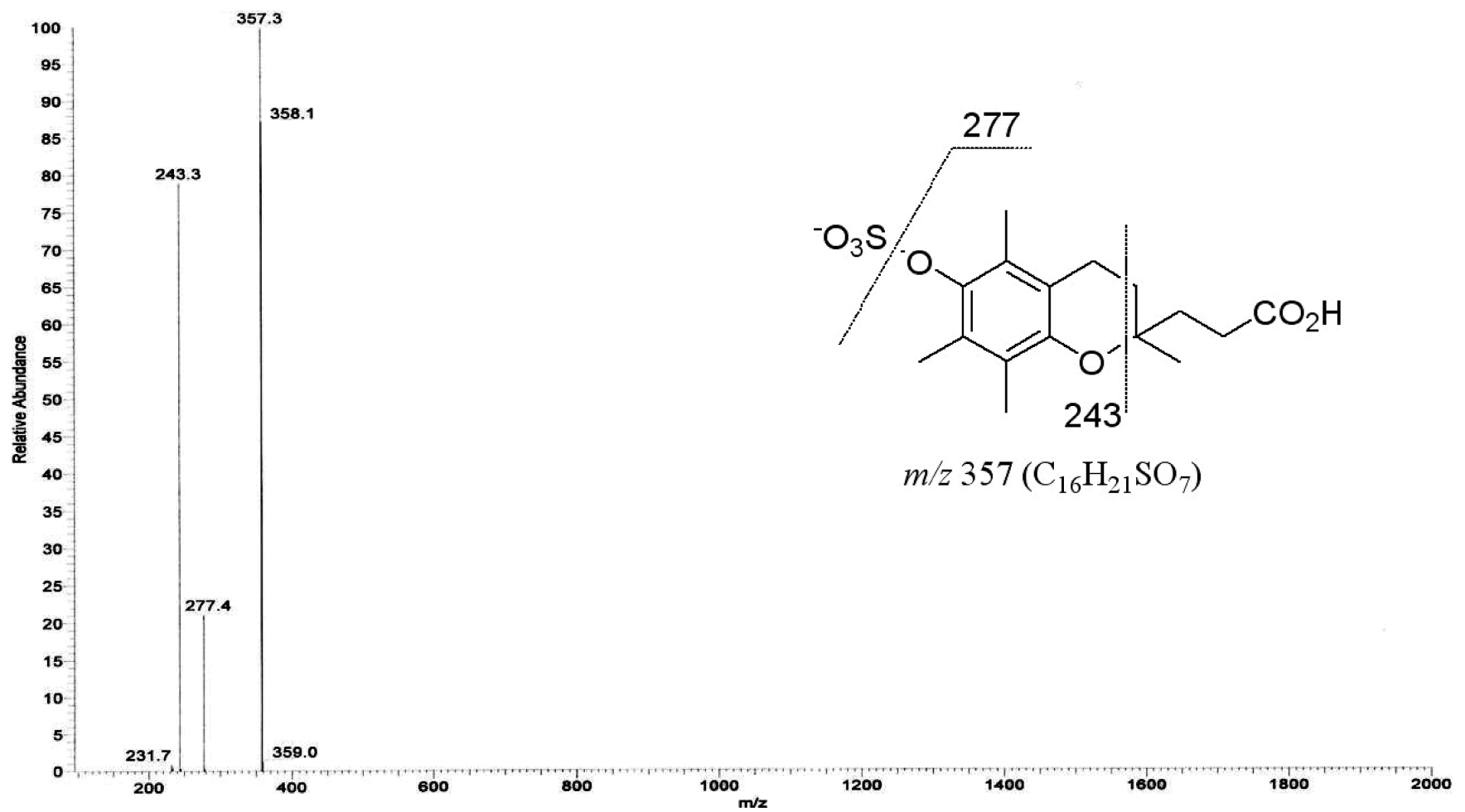

Figure 2. Negative ion ESI-MS spectra of 6 - 0 -sulfated $\alpha$-CEHC. The parent ion is $m / z 357$. The major mass fragments were $m / z 357,277$ and 243 ; these fragments were assigned as shown in the figure.

$\alpha$-CEHC. The $\alpha$-CEHC was analyzed by HPLC-ECD using a RP18 $5 \mu \mathrm{m}$ column (Keystone BetaBasic). The mobile phase was methanol $(\mathrm{MeOH}) / \mathrm{H}_{2} \mathrm{O}(43: 57, \mathrm{v} / \mathrm{v})$ containing $50 \mathrm{mM}$ sodium acetate $(\mathrm{pH} 4.5)$ at a flow rate of $1 \mathrm{~mL} / \mathrm{min}$. The guard cell was set to $250 \mathrm{mV}$. Detection and quantification of the $\alpha$-CEHC was carried out with electrochemical detection operating at an applied voltage of $150 \mathrm{mV}$, which was found to be optimal (Figure S1 in the Supporting Information; data was described in the Supporting Information). The retention time was 22-23 $\min$ for $\alpha$-CEHC. The concentration was calculated by intrapolating from an external $\alpha$-CEHC calibration curve, and the variation was recorded to assess the reproducibility. Stock solution of $\alpha$-CEHC were prepared in $\mathrm{MeOH}$ and stored at $-20{ }^{\circ} \mathrm{C}$. Working standard were prepared and calibrated daily according to its absorbance values $\varepsilon=$ $3230 \mathrm{~cm}^{-1} \times(\mathrm{mol} / \mathrm{L})^{-1}$ at $289 \mathrm{~nm}$.

$\alpha$-CEHC-Me. The HPLC-ECD analysis of $\alpha$-CEHC-Me was similar to that of $\alpha$-CEHC described above. The retention time of $\alpha$-CEHC-Me is $13 \mathrm{~min}$ in this system. The concentration was calculated by intrapolating from a calibration curve of $\alpha$-CEHC-Me prepared according to the method of Kiyose et al. (10). Pure 25, 50, 100, 200 ng of $\alpha$-CEHC were methylated with methanolic $\mathrm{HCl}$ under $\mathrm{N}_{2}$. After methylation, $\alpha$-CEHC-Me standards were extracted from the reaction mixture by the procedure for extracting this compound from testing samples described above. The extracted $\alpha$-CEHC-Me standards were analyzed by HPLC-ECD to establish the calibration curves of $\alpha$-CEHC-Me.

$\alpha$-Tocopheronolactone. The $\alpha$-tocopheronolactone was analyzed by HPLC-UV using a RP18 $5 \mu \mathrm{m}$ column (Merck Lichrospher), and the mobile phase was the same as those for $\alpha$-CEHC analysis. $\alpha$-Tocopheronolactone was detected by UV absorption at $268 \mathrm{~nm}$. Stock solutions of $\alpha$-tocopheronolactone were prepared in $\mathrm{MeOH}$ and stored at $-20{ }^{\circ} \mathrm{C}$. Working standards were prepared daily, and the concentration was calibrated by the absorbance values at $268 \mathrm{~nm}$ based on $\varepsilon=$ $22553 \mathrm{~cm}^{-1} \times(\mathrm{mol} / \mathrm{L})^{-1}$. The retention time was $23 \mathrm{~min}$ for $\alpha$-tocopheronolactone. $\alpha$-CEHC could also be detected by this HPLC $-\mathrm{UV}$ at $289 \mathrm{~nm}$, and its retention time was $21 \mathrm{~min}$, despite with much lower sensitivity.

Isolation and Identification of $\alpha$-CEHC Conjugate. Rat urine was lyophilized and then extracted with $\mathrm{MeOH}$ for deproteinization and desalting. The crude extract was separated by chromatography using an open column packed with RP-18 silica gel, eluting with a $\mathrm{CH}_{3} \mathrm{CN} /$
$\mathrm{H}_{2} \mathrm{O}$ and then $\mathrm{MeOH} / \mathrm{H}_{2} \mathrm{O}$ gradient solvent system from $0 / 100$ to $100 / 0$ $(\mathrm{v} / \mathrm{v})$. For a rapid screening of the target fractions, collected fractions were tracked by thin-layer chromatography (TLC) after $\mathrm{HCl}$ hydrolysis and $\alpha$-CEHC standard was used as the reference. The fractions containing $\mathrm{HCl}$ hydrolyzable $\alpha$-CEHC were combined and further purified by a preparative HPLC using a RP-18 column (Phenomenex Luna $5 \mu \mathrm{C} 18(2), 250 \mathrm{~mm} \times 10 \mathrm{~mm}$ ) eluting with a $50 \% \mathrm{MeOH} / \mathrm{H}_{2} \mathrm{O}$ $(\mathrm{v} / \mathrm{v})$ at a flow rate of $2 \mathrm{~mL} / \mathrm{min}$. Four fractions (fractions A-D) were obtained and screened by TLC. The fraction D was further subjected to the preparative chromatography again, eluted with $\mathrm{MeOH} / \mathrm{H}_{2} \mathrm{O}(55$ : 45 , v/v) containing $50 \mathrm{mM}$ ammonium acetate $(\mathrm{pH} \mathrm{4.5)}$ ) and a total of 13 fractions (fractions D1-D13) were obtained. The fraction D9 was then separated by HPLC with a RP-18 column eluted with $\mathrm{MeOH} /$ $\mathrm{H}_{2} \mathrm{O}(43: 57, \mathrm{v} / \mathrm{v})$ containing $50 \mathrm{mM}$ ammonium acetate $(\mathrm{pH} 4.5)$ at a flow rate of $1 \mathrm{~mL} / \mathrm{min}$ and detected by UV/vis detector operating at $289 \mathrm{~nm}$ and four fractions were collected (fractions D9-1 to D9-4). Finally, the conjugated metabolite of $\alpha$-CEHC was isolated from the fraction D9-4 (its retention time was 7-8 min). After desalting, the conjugated metabolite of $\alpha$-CEHC was identified by NMR, MS and IR spectroscopy using a Bruker 400 spectrometer, a Finnigan TSQ46C mass spectrometer and a Bio-Rad FTS-40 spectrophotometer respectively. All spectra are shown in the Supporting Information (Figure S6).

Statistical Analysis of Data. Data are expressed as means \pm SD. The statistical significance of the content of $\alpha$-CEHC in the samples obtained from different hydrolysis methods was analyzed by oneway ANOVA (analysis of variance) and Duncan's multiple range test using SAS software (SAS 9.0, Cary, NC). Results were considered to be significant at the $95 \%$ confidence level $(p<0.05)$.

\section{RESULTS}

HPLC-ECD for $\boldsymbol{\alpha}$-CEHC Analysis. Our HPLC-ECD method for $\alpha$-CEHC analysis was modified from that reported by Lodge et al. (9) in that an isocratic mobile phase was used instead of the gradient system and the applied potential was modified to $150 \mathrm{mV}$. Using this system, a sharp peak of $\alpha$-CEHC was obtained on the chromatograms for both the standard compound and the extracts of urine samples. A typical 
Table 1. ${ }^{13} \mathrm{C}$ NMR and ${ }^{1} \mathrm{H}$ NMR Spectroscopic Data for $\alpha$-CEHC, $\alpha$-CEHC Sulfate Standard and $\alpha$-CEHC Sulfate Isolated from Rat Urine (400 MHz, 100 $\mathrm{MHz}$ in $\left.\mathrm{CD}_{3} \mathrm{OD}\right)$

\begin{tabular}{|c|c|c|c|c|c|c|}
\hline \multirow[b]{3}{*}{ No. } & \multicolumn{4}{|c|}{ Standard compound } & \multirow{2}{*}{\multicolumn{2}{|c|}{$\begin{array}{c}\text { Rat urine } \\
\alpha-C E H C \text { sulfate }\end{array}$}} \\
\hline & \multicolumn{2}{|r|}{$\alpha$-CEHC } & \multicolumn{2}{|r|}{$\alpha$-CEHC sulfate ${ }^{1}$} & & \\
\hline & & $\bar{\delta}_{\mathrm{H}}(\mathrm{ppm})$ & $\bar{\delta}_{c}$ & $\bar{\delta}_{\mathrm{H}}(\mathrm{ppm})$ & $\bar{\delta}_{\mathrm{c}}$ & $\bar{\delta}_{\mathrm{H}}(\mathrm{ppm})$ \\
\hline 2 & 74.6 & & 75.3 & & 75.3 & \\
\hline $2 a$ & 23.6 & $1.21(3 \mathrm{H}, \mathrm{s})$ & 24.1 & $1.25(3 \mathrm{H}, \mathrm{s})$ & 23.8 & $1.23(3 \mathrm{H}, \mathrm{s})$ \\
\hline 3 & 32.9 & $1.75-1.82(2 \mathrm{H}, \mathrm{m})$ & 32.7 & $1.76-1.83(2 \mathrm{H}, \mathrm{m})$ & 32.7 & $1.79-1.84(2 \mathrm{H}, \mathrm{m})$ \\
\hline 4 & 21.6 & $2.62(2 \mathrm{H}, \mathrm{t}, \mathrm{J}=6.9 \mathrm{~Hz})$ & 21.6 & $2.63(2 \mathrm{H}, \mathrm{t}, J=6.9 \mathrm{~Hz})$ & 21.6 & $2.63(2 \mathrm{H}, \mathrm{t}, J=6.6 \mathrm{~Hz})$ \\
\hline 5 & 122.1 & & 128.9 & & 129.1 & \\
\hline $5 a$ & 11.8 & $2.09(3 \mathrm{H}, \mathrm{s})$ & 13.6 & $2.22(3 \mathrm{H}, \mathrm{s})$ & 13.8 & $2.22(3 \mathrm{H}, \mathrm{s})$ \\
\hline 6 & 146.2 & & 149.6 & & 149.7 & \\
\hline 7 & 124.5 & & 130.6 & & 130.8 & \\
\hline $7 a$ & 12.8 & $2.13(3 \mathrm{H}, \mathrm{s})$ & 14.6 & $2.25(3 \mathrm{H}, \mathrm{s})$ & 14.8 & $2.25(3 \mathrm{H}, \mathrm{s})$ \\
\hline 8 & 123.1 & & 123.5 & & 123.8 & \\
\hline $8 a$ & 12.0 & $2.05(3 \mathrm{H}, \mathrm{s})$ & 12.0 & $2.06(3 \mathrm{H}, \mathrm{s})$ & 12.2 & $2.05(3 \mathrm{H}, \mathrm{s})$ \\
\hline 9 & 146.4 & & 143.9 & & 144.0 & \\
\hline 10 & 118.1 & & 118.9 & & 118.6 & \\
\hline $1^{\prime}$ & 177.8 & & 178.0 & & 178.0 & \\
\hline $2^{\prime}$ & 29.6 & $2.34-2.52(2 \mathrm{H}, \mathrm{m})$ & 31.3 & $2.31-2.46(2 \mathrm{H}, \mathrm{m})$ & 29.9 & $2.38-2.56(2 \mathrm{H}, \mathrm{m})$ \\
\hline $3^{\prime}$ & 35.5 & $\begin{array}{l}1.82-1.88(1 \mathrm{H}, \mathrm{m}) \\
1.92-2.01(1 \mathrm{H}, \mathrm{m})\end{array}$ & 35.7 & $\begin{array}{l}1.83-1.89(1 \mathrm{H}, \mathrm{m}) \\
1.94-2.03(1 \mathrm{H}, \mathrm{m})\end{array}$ & 35.8 & $1.90-2.10(2 \mathrm{H}, \mathrm{m})$ \\
\hline${ }^{+} \mathrm{NH}\left(\mathrm{C}_{3}\right)_{3}$ & & & & $2.81(9 \mathrm{H}, \mathrm{s})$ & & \\
\hline
\end{tabular}

1. $\alpha$-CEHC sulfate standard is trimethylamine salt of $\alpha$-CEHC sulfate.

$\alpha$-CEHC standard calibration curve was linear from $50 \mathrm{ng} / \mathrm{mL}$ to $800 \mathrm{ng} / \mathrm{mL}(3.6-57.6 \mathrm{pmole}$, injected volume is $20 \mu \mathrm{L})$ (Figure S2 in the Supporting Information; data was shown in the Supporting Information). The method is thus applicable for samples containing a low level of $\alpha$-CEHC in biological specimens. The detection limit was $0.45 \mathrm{pmol}(125 \mathrm{pg})$ with a signal-to-noise ratio $(\mathrm{s} / \mathrm{n})$ at 2.45 . The coefficient of variation $(\mathrm{CV})$ of the slope of the standard calibration curve is lower than $5 \%$.

Enzyme Hydrolysis of Rat Urine Releases a Rather Small Amount of $\alpha$-CEHC Compared to $\mathbf{H C l}$. While $\beta$-glucuronidase was employed to hydrolyze the conjugated $\alpha$-CEHC in the rat urine samples as reported $(7,9)$, about 6-fold of $\alpha$-CEHC was detected as compared to the value without any pretreatment (free $\alpha$-CEHC) $(2.17 \pm 0.52 \mu \mathrm{M}$ v.s. $0.33 \pm 0.07$ $\mu \mathrm{M})$. Increasing the amount of enzyme could not increase the amount of $\alpha$-CEHC detected from the rat urine. In contrast, adding $\mathrm{HCl}$ vastly increased the peak area at the retention time of 22-23 min. By a calculation based on the calibration curve, the peak area was estimated to be equivalent to 280 -fold that of the free $\alpha$-CEHC $(92.59 \pm 1.04 \mu \mathrm{M}$ vs $0.33 \pm 0.07 \mu \mathrm{M})$. To examine the chemical identity of the compound of this large peak, a preparative HPLC was used to separate, isolate and purify the compound. The identical ${ }^{1} \mathrm{H}$ NMR spectrum to that of the authentic $\alpha$-CEHC standard indicated that the peak eluted at 22-23 min after $\mathrm{HCl}$ pretreatment of rat urine is indeed $\alpha$-CEHC (Figure S4 in the Supporting Information; data was described detailed in the Supporting Information).
Identification of the $\mathrm{HCl}$ Releasable $\alpha$-CEHC Conjugate in the Rat Urine. To identify the $\mathrm{HCl}$ releasable $\alpha$-CEHC conjugate, rat urine samples were freeze-dried, extracted and separated by flash column chromatography and preparative HPLC (Figure S5 in the Supporting Information; the isolated flowchart and chromatograms were shown in the Supporting Information). The fraction D9-4 contained the target compound that can release $\alpha-\mathrm{CEHC}$ after $\mathrm{HCl}$ hydrolysis. As shown in Figure 2, the electron impact mass spectrum indicated that the $\alpha$-CEHC conjugate has an exact molecular weight of 357 and its major fragments are $\mathrm{m} / \mathrm{z}$. 243 and 277. The $\mathrm{m} / \mathrm{z}, 243$ ion is resulted from a fragmentation at the 3,4 carbon-carbon and oxygen-carbon bond at $\mathrm{C} 2$ of the chroman ring. The fragment of $\mathrm{m} / \mathrm{z}, 277$ corresponds to a loss of 80 unit which is a characteristic fragment of sulfur trioxide $\left(\mathrm{SO}_{3}{ }^{-}\right)$. The ${ }^{1} \mathrm{H}$ and ${ }^{13} \mathrm{C}$ NMR spectrum (Table 1) of the $\alpha$-CEHC conjugate shows chemical shifts indicating changes on the $\mathrm{C} 6$ of the chroman ring. The fragment of $\mathrm{m} / \mathrm{z} 357,243,277$ in the MS along with the similarity of the NMR chemical shifts to the $\alpha-\mathrm{CEHC}$ led to the proposed structure of the conjugated $\alpha-\mathrm{CEHC}$ in the rat urine is $6-O$-sulfated $\alpha$-CEHC ( $\alpha$-CEHC sulfate) which best fit the formula $\mathrm{C}_{16} \mathrm{H}_{21} \mathrm{O}_{7} \mathrm{~S}$. The characteristic of sulfate (1232 and $\left.1001 \mathrm{~cm}^{-1}\right)$ and carboxylic acid $\left(2700-3300 \mathrm{~cm}^{-1}\right)$ in the IR also support the chemical structure elucidated. This structure was confirmed by the unambiguous synthesis of $\alpha$-CEHC sulfate from $\alpha-\mathrm{CEHC}$ and trimethylamine $-\mathrm{SO}_{3}$ complex. The purity of $\alpha-\mathrm{CEHC}$ sulfate in the fraction D9-4 is about $86 \%$. Accordingly, the sulfate conjugate is identified as the compound in rat urine that can release $\alpha-\mathrm{CEHC}$ by $\mathrm{HCl}$. 
(A)

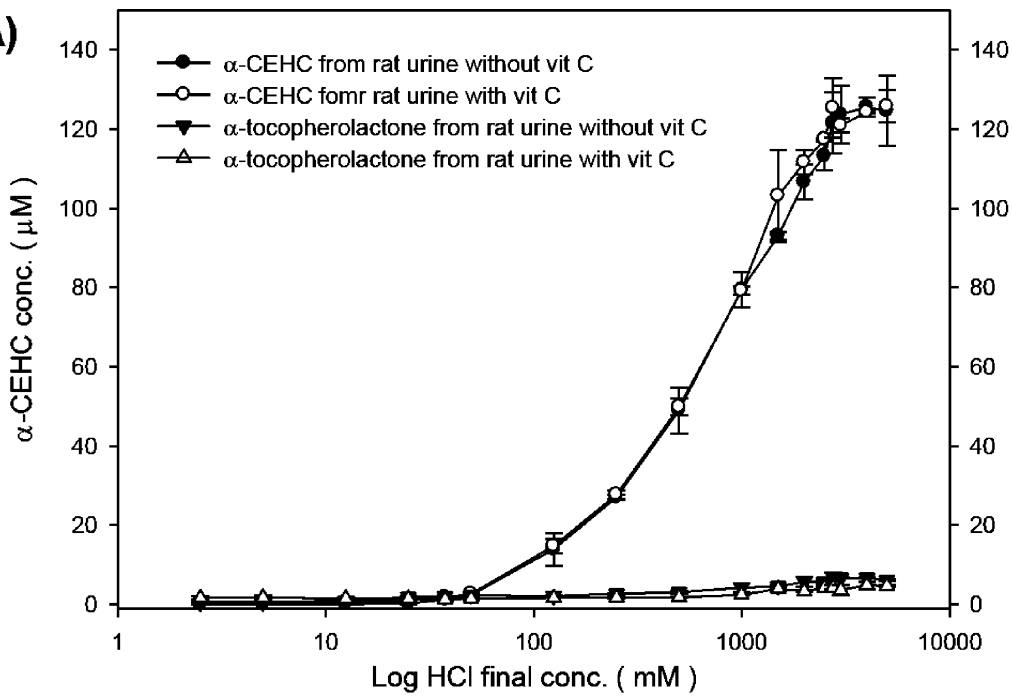

(B)

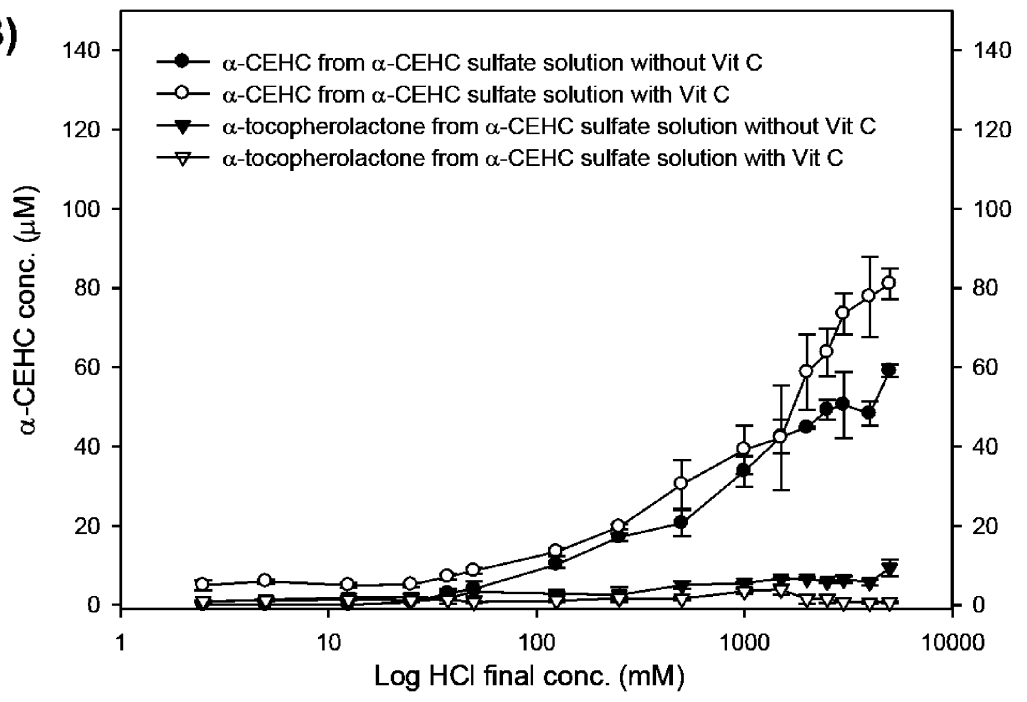

(C)

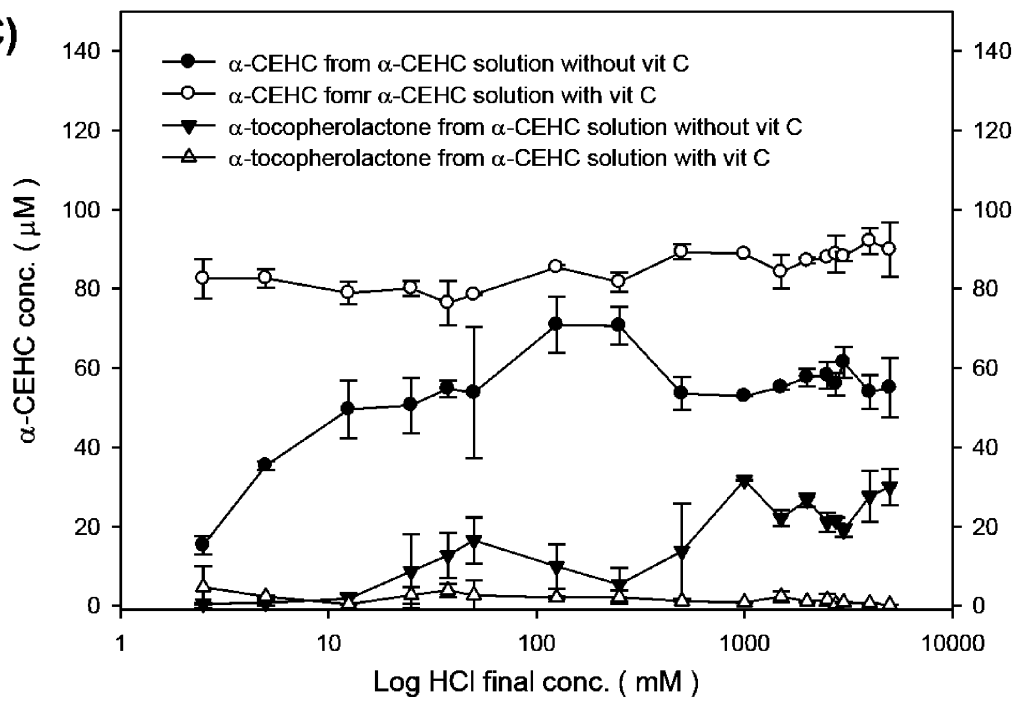

\begin{tabular}{ccc}
\hline $\begin{array}{c}\text { HCl } \\
\text { conc. }\end{array}$ & -Vit C & +Vit C \\
\cline { 2 - 3 } ( mM $)$ & pH & pH \\
\hline 0 & 7.48 & 3.94 \\
2.5 & 7.15 & 3.81 \\
5 & 6.92 & 3.61 \\
12.5 & 6.37 & 3.06 \\
25 & 3.33 & 2.18 \\
37.5 & 2.26 & 1.85 \\
50 & 1.89 & 1.69 \\
125 & 1.67 & 1.43 \\
250 & 1.08 & 1.25 \\
500 & 0.86 & 0.71 \\
1000 & 0.72 & 0.63 \\
1500 & 0.62 & 0.3 \\
2000 & 0.36 & 0.21 \\
2500 & 0.29 & 0.16 \\
$\mathbf{3 0 0 0}$ & 0.00 & 0.06 \\
4000 & -0.14 & -0.04 \\
$\mathbf{5 0 0 0}$ & -0.29 & -0.20 \\
\hline & &
\end{tabular}

\begin{tabular}{ccc}
\hline HCl & - Vit C & +Vit C \\
\cline { 2 - 3 }$(\mathbf{m M})$ & pH & pH \\
\hline 0 & 8.75 & 4.42 \\
2.5 & 8.21 & 4.23 \\
5 & 7.88 & 4.14 \\
12.5 & 7.16 & 3.81 \\
25 & 6.19 & 3.01 \\
37.5 & 1.90 & 1.82 \\
50 & 1.61 & 1.70 \\
125 & 1.10 & 1.03 \\
250 & 0.73 & 0.70 \\
500 & 0.33 & 0.56 \\
1000 & 0.05 & 0.10 \\
1500 & -0.02 & -0.06 \\
2000 & -0.17 & -0.20 \\
2500 & -0.19 & -0.27 \\
3000 & -0.35 & -0.37 \\
4000 & -0.52 & -0.44 \\
5000 & -0.75 & -0.67 \\
\hline & &
\end{tabular}

\begin{tabular}{|c|c|c|}
\hline \multirow{2}{*}{$\begin{array}{c}\mathrm{HCl} \\
\text { conc. } \\
\text { ( } \mathrm{mM})\end{array}$} & -Vit C & +Vit C \\
\hline & pH & pH \\
\hline 0 & 7.25 & 3.32 \\
\hline 2.5 & 7.11 & 3.04 \\
\hline 5 & 6.94 & 2.77 \\
\hline 12.5 & 2.48 & 2.13 \\
\hline 25 & 2.07 & 1.75 \\
\hline 37.5 & 1.9 & 1.57 \\
\hline 50 & 1.76 & 1.44 \\
\hline 125 & 1.41 & 1.11 \\
\hline 250 & 1.19 & 0.92 \\
\hline 500 & 0.89 & 0.71 \\
\hline 1000 & 0.67 & 0.51 \\
\hline 1500 & 0.54 & 0.36 \\
\hline 2000 & 0.38 & 0.22 \\
\hline 2500 & 0.27 & 0.11 \\
\hline 3000 & 0.09 & -0.03 \\
\hline 4000 & -0.01 & -0.17 \\
\hline 5000 & -0.17 & -0.31 \\
\hline
\end{tabular}

Figure 3. The effect of various concentrations of $\mathrm{HCl}$ on the $\alpha-\mathrm{CEHC}$ and $\alpha$-tocopheronolactone measured from (A) rat urine, (B) $\alpha$-CEHC sulfate standard $(78.6 \mu \mathrm{M})$ and $(\mathbf{C}) \alpha-\mathrm{CEHC}$ standard $(89.9 \mu \mathrm{M})$ with or without ascorbate protection.

Establish the Procedure for the Analysis of $\alpha$-CEHC in Rat Urine by Acid Hydrolysis and HPLC-ECD. Various concentrations of $\mathrm{HCl}$ were added to authentic $\alpha$-CEHC sulfate solution or rat urine for the determination of the amount of $\mathrm{HCl}$ needed. The $\mathrm{pH}, \alpha$-CEHC and $\alpha$-tocopheronolactone detected are shown in Figure 3. A threshold $\mathrm{HCl}$ concentration is needed for the release of $\alpha$-CEHC from the rat urine and $\alpha$-CEHC sulfate solution. Above this threshold, the amount of released $\alpha$-CEHC increased dose-dependently with the increase of $\mathrm{HCl}$ concentration. When the final concentration of $\mathrm{HCl}$ added reached $3 \mathrm{~N}$, the maximal amount of $\alpha$-CEHC is released from both rat urine and $\alpha$-CEHC sulfate solution (Figure 3A, 3B). As $\alpha$-CEHC has been shown to be oxidized to $\alpha$-tocopheronolactone (4), we also examined whether this can be protected by 

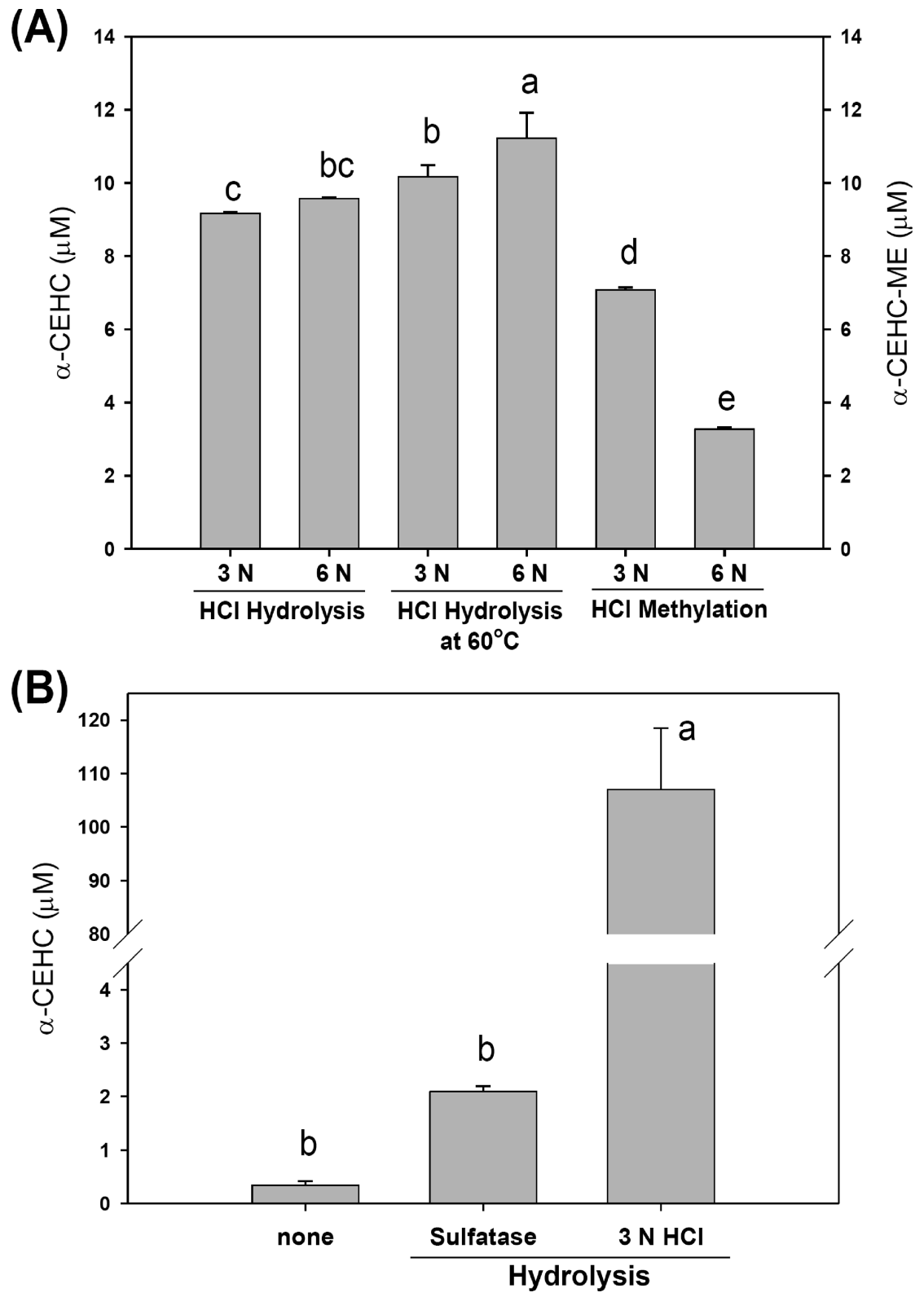

Figure 4. Comparison of various hydrolysis procedures for the analysis of $\alpha-\mathrm{CEHC}$ in rat urine. Rat urine samples containing $20 \mathrm{mg} / \mathrm{mL}$ ascorbate to adjust $\mathrm{pH}$ value to near 4 were collected from rats fed the AlV-76 modified diets containing $50 \mathrm{mg} / \mathrm{kg}(\mathbf{A})$ or $500 \mathrm{mg} / \mathrm{kg} \mathrm{diet} \mathrm{(B)} \mathrm{of} \mathrm{all-rac-} \alpha$-tocopheryl acetate. Aliquots of urine samples were hydrolyzed by sulfatase, $\mathrm{HCl}$ (final concentration 3 or $6 \mathrm{~N}$ ) at room temperature, $\mathrm{HCl}$ at $60{ }^{\circ} \mathrm{C}$ for one hour (final concentration 3 or $6 \mathrm{~N}$ ). In (B) aliquots of samples were also deconjugated by methanolic $\mathrm{HCl}$ (final concentration 3 or $6 \mathrm{~N}$ ) at $60^{\circ} \mathrm{C}$ which produce and can be detected as $\alpha$-CEHC-Me. Values are means \pm SD of $2-8$ independent experiments. Values not sharing a common letter are significantly different from one another by oneway ANOVA and Duncan's multiple range test $(p<0.05)$.

adding ascorbate as an antioxidant. In the presence of ascorbate, more $\alpha$-CEHC and less $\alpha$-tocopheronolactone were detected when the $\alpha$-CEHC sulfate solutions were treated with high concentrations of $\mathrm{HCl}$ (Figure 3B). The protective effect of ascorbate in the $\mathrm{HCl}$ pretreatment was less apparent for rat urine (Figure 3A), but most dramatic for the $\alpha$-CEHC solution (Figure 3C). In the latter case, the recovery of $\alpha$-CEHC was near $100 \%$ and $60 \%$, respectively, in the presence and absence of ascorbate. Therefore, it is demonstrated that ascorbate could protect $\alpha$-CEHC in $\mathrm{HCl}$ hydrolysis. It is interesting to note that adding ascorbate lowered the $\mathrm{pH}$ of $\alpha$-CEHC solution to about 4 , which might render the $\alpha-\mathrm{CEHC}$ existing as the protonated form and could be extracted almost completely without adding $\mathrm{HCl}$ (Figure 3C).

To obtain a valid acid hydrolysis procedure, the released amount of $\alpha$-CEHC and $\alpha$-tocopheronolactone production were monitored while $\alpha$-CEHC sulfate solution was hydrolyzed with various conditions. As shown in Table 2, acid hydrolysis with $6 \mathrm{~N} \mathrm{HCl}$ at $60{ }^{\circ} \mathrm{C}$ for one hour resulted in the highest amount of $\alpha$-CEHC detected. Under the protection of ascorbate, the production of $\alpha$-tocopheronolactone was minimal and the recovery of $\alpha$-CEHC from the $\alpha$-CEHC sulfate solution was over $100 \%$ through this process of acid hydrolysis at $60{ }^{\circ} \mathrm{C}$ (Table 3).

For comparison, the acid hydrolysis coupled with methylation method reported by Kiyose et al. (10) was also examined. This method which measures total CEHC after free and conjugated CEHC in samples were converted to CEHC-Me has been employed in many studies $(21-24)$. As shown in Table 2 and Figure 4A, the amount $\alpha$-CEHC obtained from $6 \mathrm{~N} \mathrm{HCl}$ acid hydrolysis at $60{ }^{\circ} \mathrm{C}$ for one hour is significantly higher than the amount of $\alpha$-CEHC-Me derived from acid methylation. Notice- 
Table 2. The production of $\alpha-\mathrm{CEHC}$ and $\alpha$-Tocopheronolactone from $\alpha$-CEHC Sulfate Standard by Various Hydrolysis Procedures

\begin{tabular}{|c|c|c|c|c|c|c|c|c|}
\hline & \multirow[b]{2}{*}{ none } & \multirow[b]{2}{*}{ sulfatase $^{b}$} & \multirow[b]{2}{*}{ sulfatase $+3 \mathrm{~N} \mathrm{HCl}^{b}$} & \multicolumn{3}{|c|}{ acid hydrolysis ${ }^{b}$} & \multicolumn{2}{|c|}{ acid methylation ${ }^{c}$} \\
\hline & & & & $3 \mathrm{~N} \mathrm{HCl}$ & $6 \mathrm{~N} \mathrm{HCl}$ & $6 \mathrm{~N} \mathrm{HCl}$ at $60^{\circ} \mathrm{C}$ & $3 \mathrm{~N} \mathrm{HCl}$ & $6 \mathrm{~N} \mathrm{HCl}$ \\
\hline$\overline{\alpha-C E H C ~(\mu \mathrm{M})}$ & $0.01 \pm 0.00 e^{a, d}$ & $0.03 \pm 0.01 \mathrm{e}$ & $58.1 \pm 3.4 c$ & $56.8 \pm 9.4 c$ & $63.3 \pm 9.5 b$ & $82.5 \pm 7.8 \mathrm{a}$ & $43.7 \pm 1.0 \mathrm{~d}$ & $55.7 \pm 0.7 c$ \\
\hline$N^{a}$ & 4 & 5 & 6 & 23 & 9 & 9 & 2 & 2 \\
\hline $\begin{array}{l}\alpha \text {-tocopheronolactone }(\mu \mathrm{M}) \\
\%\end{array}$ & ND & ND & $\begin{array}{l}0.28 \pm 0.15 b \\
0.36\end{array}$ & $\begin{array}{l}0.65 \pm 0.22 b \\
0.83\end{array}$ & $\begin{array}{l}1.00 \pm 0.15 b \\
1.27\end{array}$ & $\begin{array}{l}3.69 \pm 2.55 a \\
4.69\end{array}$ & & \\
\hline$N$ & 2 & 3 & 3 & 15 & 3 & 6 & & \\
\hline
\end{tabular}

\footnotetext{
${ }^{a}$ Each value represents mean \pm SD. ND, nondetectable. $N$ indicates the number of independent experiments. ${ }^{b} 78.6 \mu \mathrm{M} \alpha-\mathrm{CEHC}$ sulfate solution (trimethylamine salt of $\alpha$-CEHC sulfate MW $477,37.5 \mu \mathrm{g} / \mathrm{mL}$ ) contains $20 \mathrm{mg} / \mathrm{mL}$ ascorbic acid (pH value around 4) were respectively hydrolyzed by sulfatase, sulfatase followed by $\mathrm{HCl}$ (final concentration $3 \mathrm{~N}$ ), $\mathrm{HCl}$ (final concentration 3 or $6 \mathrm{~N}$ ) at room temperature, $\mathrm{HCl}$ at $60^{\circ} \mathrm{C}$ for one hour (final concentration 3 or $6 \mathrm{~N}$ ). $\alpha-\mathrm{CEHC}$ released was analyzed by $\mathrm{HPLC}-\mathrm{ECD}$ using $\mathrm{MeOH} / \mathrm{H}_{2} \mathrm{O}=43 / 57$ (the aqueous phase contains $50 \mathrm{mM}$ ammonium acetate, $\mathrm{pH}$ 4.5) as the mobile phase. $\alpha$-Tocopheronolactone was analyzed by $\mathrm{HPLC}-\mathrm{UV}$ at $268 \mathrm{~nm}$ with the same mobile phase system. ${ }^{c}$ For comparison, the sulfate $\alpha-\mathrm{CEHC}$ solution was also deconjugated by methanolic $\mathrm{HCl}$ (final concentration $3 \mathrm{~N}$ or $6 \mathrm{~N}$ ) at $60{ }^{\circ} \mathrm{C}$ for $1 \mathrm{~h}$. The $\alpha$-CEHC-Me produced was analyzed by HPLC-ECD using $\mathrm{CH}_{3} \mathrm{CN} / \mathrm{H}_{2} \mathrm{O}=43 / 57$ (the aqueous phase contains $50 \mathrm{mM}$ ammonium acetate, $\mathrm{pH} 4.5$ ) as the mobile phase. ${ }^{d}$ Values not sharing a common letter a,b,c,d,e are significantly different from one another in a horizontal row by oneway ANOVA and Duncan's multiple range test $(p<0.05)$.
}

Table 3. The Recovery Test of the $\alpha$-CEHC Analysis by Spiking the $\alpha$-CEHC or $\alpha$-CEHC Sulfate Standard before Acid Hydrolysis

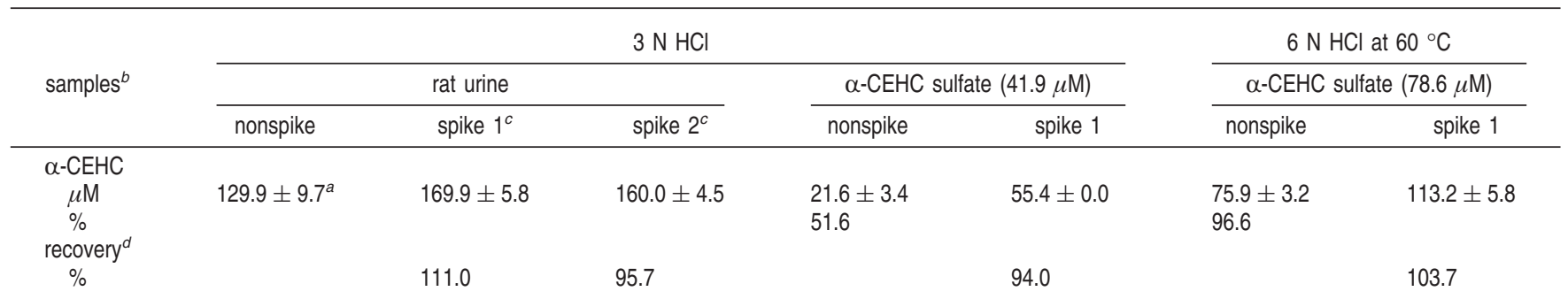

\footnotetext{
${ }^{a}$ Each value represents mean $\pm \mathrm{SD}$ of 2 to 5 independent experiments. ${ }^{b}$ Rat urine was collected from rats fed an AIN-76 modified diet containing $500 \mathrm{mg} / \mathrm{kg}$ diet of all-rac- $\alpha$-tocopheryl acetate. $\alpha$-CEHC sulfate standard is dissolved in $60 \mathrm{mM} \mathrm{Na} 2 \mathrm{HCO}_{3}$ solution to a final concentration of 41.9 or $78.6 \mu \mathrm{M}$. Both contained $20 \mathrm{mg} / \mathrm{mL}$ ascorbic acid and were hydrolyzed with $\mathrm{HCl}$ (final concentration $3 \mathrm{~N}$ ) at room temperature or $\mathrm{HCl}$ at $60{ }^{\circ} \mathrm{C}$ for $1 \mathrm{~h}$ (final concentration $6 \mathrm{~N}$ ). $\alpha$-CEHC released was extracted by diethyl ether and analyzed by HPLC-ECD using $\mathrm{MeOH} / \mathrm{H}_{2} \mathrm{O}=43 / 57$ (aqueous phase contains $50 \mathrm{mM}$ sodium acetate, pH 4.5) as the mobile phase. ${ }^{c}$ Spike 1 and 2 respectively indicate the samples were added with $35.97 \mathrm{nmol}$ of $\alpha$-CEHC $(\alpha-\mathrm{CEHC}$ MW $278,10 \mu \mathrm{g}$ ) or $31.44 \mathrm{nmol}$ of $\alpha$-CEHC sulfate (trimethylamine salt of $\alpha$-CEHC sulfate MW $477,15 \mu \mathrm{g}){ }^{d}$ Recovery $(\%)=[($ spike - non-spike $) / 35.97$ or 31.44$] \times 100$.
}

ably, sulfatase released very minimal amount of $\alpha$-CEHC from $\alpha$-CEHC sulfate solution and rat urine samples, unless high concentration of $\mathrm{HCl}$ was added after enzyme reaction before the extraction procedure (Table 2, Figure 4B).

The recovery of $\alpha$-CEHC by the procedure established was further validated by spiking rat urine samples or $\alpha$-CEHC sulfate solution with $\alpha$-CEHC or $\alpha$-CEHC sulfate standards. The recovery ranged from 96 to $111 \%$ (Table 3 ).

\section{DISCUSSION}

All forms of tocopherols and tocotrienols $(\alpha, \beta, \gamma$ and $\delta)$ are metabolized to CEHCs $(25,26)$. However, there is disagreement in the detection of conjugated forms of CEHCs in urine samples $(4,18-20)$. Despite the disagreement, hydrolyzed with $\beta$-glucuronidase is still the most widely employed process before the extraction for analyzing CEHCs in specimens from humans (14), rats $(15)$ or mice $(16,17)$. However, we observed that pretreatment of rat urine with $\beta$-glucuronidase (with sulfatase activity) or sulfatase released only very small amount of $\alpha$-CEHC (Table 2 ) in contrast to a vast amount released by $\mathrm{HCl}$ hydrolysis. We then used the release of $\alpha$-CEHC by $\mathrm{HCl}$ to track the original chemical species and found that $\alpha-\mathrm{CEHC}$ sulfate is the $\mathrm{HCl}$ releasable conjugate of $\alpha-\mathrm{CEHC}$ in the rat urine. It is known that ester linkage of a sulfate conjugate could be hydrolyzed by acid catalysis, especially with high concentration of $\mathrm{HCl}$. This is in agreement with our observation that $\mathrm{HCl}$ dose-dependently released $\alpha$-CEHC from rat urine and $\alpha$-CEHC sulfate solution. Together with the result that $\beta$-glucuronidase only released very limited amount of $\alpha-\mathrm{CEHC}$, it is suggested that sulfate conjugate might be the dominant conjugate form of $\alpha$-CEHC in rat urine. This is also in agreement with the observation on $\gamma$-CEHC of Tanabe et al. (18).

Surprisingly, sulfatase has very low efficiency in hydrolyzing $\alpha$-CEHC sulfate. Chiku et al. (5) isolated the metabolite of $\delta$-tocopherol from the urine of rats given radioactive $\delta$-tocopherol by TLC after hydrolysis of conjugates with sulfatase in various conditions. By treatment with sulfatase in acetate buffer, radioactivity moved far from the origin; but in a buffer containing phosphate ion, radioactivity remained at the origin. Their results indicated that the phosphate ion is a sulfatase inhibitor and the urinary metabolite of $\delta$-tocopherol was excreted as conjugates of sulfate. Based on this report, we have tried to improve the condition of enzyme reaction by excluding the phosphate ion in the reaction mixture of sulfatase and the $\alpha$-CEHC sulfate standard. The release of free $\alpha$-CEHC, however, was still very low. In contrast, the sulfatase could hydrolyze its optimal substrate $p$-nitrocatechol sulfate to produce $p$-nitrocatechol and free sulfate efficiently in acetate buffer (data not shown). The sulfatase used in our study is thus indeed active. Therefore, the inefficiency of sulfatase hydrolysis of $\alpha$-CEHC sulfate is speculated to be attributed to the number of methyl groups substituted in the chroman ring which has exerted a steric hindrance that might interfere in the catalytic function of the sulfatase enzyme. $\delta$-CEHC sulfate, in contrast, with only one methyl group at the meta-position to the sulfate group on the chroman ring, was shown to be hydrolyzable with sulfatase. It is not known whether such interference also 
existed in the hydrolysis of $\alpha$-CEHC glucuronide by the glucuronidase enzyme.

Using our synthetic $\alpha$-CEHC sulfate, we found that acid hydrolysis with $6 \mathrm{~N} \mathrm{HCl}$ at $60{ }^{\circ} \mathrm{C}$ for one hour almost completely hydrolyzed the conjugate. Schultz et al. (4) showed an almost complete conversion of $\alpha$-CEHC to $\alpha$-tocopheronolactone after bubbling oxygen to a solution of $70 \mu \mathrm{M} \alpha$-CEHC in $0.1 \mathrm{M} \mathrm{HCl}$ for $24 \mathrm{~h}$ at room temperature, suggesting that urinary $\alpha$-tocopheronolactone found in the early report might be artificially produced through the chemical isolation process. However, Pope et al. (13) has been able to detect $\alpha$-tocopheronolactone, in human urine and speculated it as an indicator of in vivo oxidative stress. Irrespective the origin of the $\alpha$-tocopheronolactone in the urine, our procedure of including a high concentration of ascorbate as an antioxidant could keep the production of $\alpha$-tocopheronolactone at a minimal level through the acid hydrolysis with heat.

A number of reports employed the method of Kiyose et al. (10) to detect CEHC by methylation coupled to acid hydrolysis using methanolic $\mathrm{HCl}$. CEHC-Me is considered to be more stable that can prevent the artificial production of tocopheronolactone. This method was also conducted in this study for a comparison to our procedure of acid hydrolysis with heat. Using the $\alpha$-CEHC sulfate solution, it was observed that acid methylation resulted in the detection of about $70 \%$ of $\alpha$-CEHC, in contrast to about $105 \%$ by our procedure. Similarly, the amount of $\alpha$-CEHC in the rat urine sample detected by our procedure of acid hydrolysis with heat was significantly higher than the acid methylation process (Figure $\mathbf{4 A}$ ).

Our HPLC-ECD method for the measurement of $\alpha$-CEHC was modified from Lodge et al. (9) by changing the voltage in the detection of ECD and by using mobile phase without gradient. Furthermore, an external calibration curve was used instead of the internal standard. In addition to measure the amount of total $\alpha$-CEHC by prior acid hydrolysis with heat, free form of $\alpha$-CEHC can also be determined by acidifying the urine samples to $\mathrm{pH} 4$ with ascorbate prior to extraction. Using ascorbic acid to acidify to a $\mathrm{pH}$ of 4 can adequately protonate $\alpha$-CEHC for complete extraction but avoid the hydrolysis of the conjugated form by adding $\mathrm{HCl}$. Therefore, the amount of $\alpha$-CEHC extracted under $\mathrm{pH} 4$ can be defined as the amount of free $\alpha$-CEHC in the samples. On the other hand, the amount of $\alpha$-CEHC extracted after $6 \mathrm{~N} \mathrm{HCl}$ at $60{ }^{\circ} \mathrm{C}$ for one hour in the presence of ascorbate can be defined as the amount of total $\alpha$-CEHC in the samples, which includes free and all conjugated $\alpha$-CEHC. Stahl et al. (7) reported that about 35\% of total $\alpha$-CEHC was present as glucuronide conjugate in human serum but $\gamma$-CEHC are all present as the free form. Lodge et al. (9) indicated that, for both $\alpha$ - and $\gamma$-CEHC, the free form typically comprises from 5 to $25 \%$ of the total metabolites in human urine. In our study, over $99.6 \%$ of $\alpha$-CEHC in the rat urine existed in the conjugated forms. Based on our result (Figure 3), it is probable that, even without enzyme hydrolysis, a significant proportion of the sulfate conjugate has been hydrolyzed while acidified with $\mathrm{HCl}$ to lower $\mathrm{pH}$ before extraction.

The pathway in which vitamin E is catabolized to CEHC and its conjugate is speculated to be mediated by phase I and phase II enzymes that are responsible for the elimination of drugs, xenobiotics as well as endogeneous compounds with low solubility. The phase I enzyme reaction might be cytochrome $\mathrm{P}-450$ mediated $\omega$-hydroxylation which is followed by stepwise $\beta$-oxidation of the phytyl side chain. The phase II enzymes, such as UDP glucuronosyl transferases (UGTs) and sulfotransferase, then catalyze the conjugation reaction before the final metabolites are excreted in urine or bile $(26,27)$. Since we found that $\mathrm{HCl}$ can release such a large amount of $\alpha$-CEHC from rat urine and the $\mathrm{HCl}$ releasable form was identified to be $\alpha$-CEHC sulfate, it is conceivable that $\alpha$-CEHC sulfate is the major and dominate form of $\alpha$-CEHC in rat urine. Indeed, Jiang et al. (12) also identified sulfated long-chain carboxychromanols (sulfated 9'-, 11'-, and 13'-carboxychromanol) as novel vitamin E metabolites from the human A549 cells or rats treated with $\gamma$ - or $\delta$-tocopherol and they further provided evidence that sulfation may occur parallel with $\beta$-oxidation. Therefore, sulfation may play an important role in the vitamin E catabolism and merit further investigation.

In conclusion, we observed that $\mathrm{HCl}$ can release a very large amount of $\alpha$-CEHC from rat urine. This acid releasable conjugate was isolated, purified and identified to be $\alpha$-CEHC sulfate. A relatively simple and rapid method for the measurement of $\alpha$-CEHC was then developed. In this procedure, samples are added with ascorbate as the antioxidant, acid hydrolyzed with heat, extracted by diethyl ether and analyzed by HPLC-ECD. The method is sensitive and reproducible and can be used for further study of the vitamin E catabolism to $\alpha$-CEHC.

\section{ABBREVIATIONS USED}

$\alpha$-TOH, $\alpha$-tocopherol; $\alpha$-CEHC, 2,5,7,8-tetramethyl-2-(2'carboxyethyl)-6-hydroxychroman; $\alpha$-CEHC sulfate, 6- $O$-sulfated $\alpha$-CEHC; $\alpha$-CEHC-Me, $\alpha$-CEHC methyl ester; HPLC-ECD, high performance liquid chromatography-electrochemical detector.

Supporting Information Available: The procedure of chemical synthesis of standard compound, chromatography and standard calibration curve of $\alpha$-CEHC standard, and isolation procedure and spectra of the vitamin E metabolite in rat urine are available free of charge via the Internet at http:// pubs.acs.org.

\section{LITERATURE CITED}

(1) Brigelius-Flohe, R.; Traber, M. G. Vitamin E: function and metabolism. FASEB J. 1999, 13 (10), 1145-55.

(2) Jiang, Q.; Christen, S.; Shigenaga, M. K.; Ames, B. N. Gammatocopherol, the major form of vitamin $\mathrm{E}$ in the US diet, deserves more attention. Am. J. Clin. Nutr. 2001, 74 (6), 714-22.

(3) Eisengart, A.; Milhorat, A. T.; Simon, E. J.; Sundheim, L. The metabolism of vitamin E. II. Purification and characterization of urinary metabolites of alpha-tocopherol. J. Biol. Chem. 1956, 221 (2), 807-17.

(4) Schultz, M.; Leist, M.; Petrzika, M.; Gassmann, B.; BrigeliusFlohe, R. Novel urinary metabolite of alpha-tocopherol, 2,5,7,8tetramethyl-2(2'-carboxyethyl)-6-hydroxychroman, as an indicator of an adequate vitamin E supply? Am. J. Clin. Nutr. 1995, 62 (6), 1527S-1534S.

(5) Chiku, S.; Hamamura, K.; Nakamura, T. Novel urinary metabolite of d-delta-tocopherol in rats. J. Lipid Res. 1984, 25 (1), 40-8.

(6) Swanson, J. E.; Ben, R. N.; Burton, G. W.; Parker, R. S. Urinary excretion of 2,7, 8-trimethyl-2-(beta-carboxyethyl)-6-hydroxychroman is a major route of elimination of gamma-tocopherol in humans. J. Lipid Res. 1999, 40 (4), 665-71.

(7) Stahl, W.; Graf, P.; Brigelius-Flohe, R.; Wechter, W.; Sies, H. Quantification of the alpha- and gamma-tocopherol metabolites 2,5,7, 8-tetramethyl-2-(2'-carboxyethyl)-6-hydroxychroman and 2,7, 8-trimethyl-2-(2'-carboxyethyl)-6-hydroxychroman in human serum. Anal. Biochem. 1999, 275 (2), 254-9.

(8) Himmelfarb, J.; Kane, J.; McMonagle, E.; Zaltas, E.; Bobzin, S.; Boddupalli, S.; Phinney, S.; Miller, G. Alpha and gamma tocopherol metabolism in healthy subjects and patients with endstage renal disease. Kidney Int. 2003, 64 (3), 978-91. 
(9) Lodge, J. K.; Traber, M. G.; Elsner, A.; Brigelius-Flohe, R. A rapid method for the extraction and determination of vitamin $\mathrm{E}$ metabolites in human urine. J. Lipid Res. 2000, 41 (1), 148-54.

(10) Kiyose, C.; Saito, H.; Kaneko, K.; Hamamura, K.; Tomioka, M.; Ueda, T.; Igarashi, O. Alpha-tocopherol affects the urinary and biliary excretion of 2,7,8-trimethyl-2 (2'-carboxyethyl)-6-hydroxychroman, gamma-tocopherol metabolite, in rats. Lipids 2001, 36 (5), 467-72.

(11) Hattori, A.; Fukushima, T.; Imai, K. Occurrence and determination of a natriuretic hormone, 2,7,8-trimethyl-2-(beta-carboxyethyl)6-hydroxy chroman, in rat plasma, urine, and bile. Anal. Biochem. 2000, 281 (2), 209-15.

(12) Jiang, Q.; Freiser, H.; Wood, K. V.; Yin, X. Identification and quantitation of novel vitamin E metabolites, sulfated long-chain carboxychromanols, in human A549 cells and in rats. J. Lipid Res. 2007, 48 (5), 1221-30.

(13) Pope, S. A.; Clayton, P. T.; Muller, D. P. A new method for the analysis of urinary vitamin $\mathrm{E}$ metabolites and the tentative identification of a novel group of compounds. Arch. Biochem. Biophys. 2000, 381 (1), 8-15.

(14) Yoshikawa, S.; Morinobu, T.; Hamamura, K.; Hirahara, F.; Iwamoto, T.; Tamai, H. The effect of [gamma]-tocopherol administration on [alpha]-tocopherol levels and metabolism in humans. Eur. J. Clin. Nutr. 2005, 59, 900-5.

(15) Leonard, S. W.; Gumpricht, E.; Devereaux, M. W.; Sokol, R. J.; Traber, M. G. Quantitation of rat liver vitamin E metabolites by LC-MS during high-dose vitamin $\mathrm{E}$ administration. J. Lipid Res. 2005, 46, 1068-75.

(16) Kluth, D.; Landes, N.; Pfluger, P.; Muller-Schmehl, K.; Weiss, K.; Bumke-Vogt, C.; Ristow, M.; Brigelius-Flohe, R. Modulation of Cyp3a11 mRNA expression by alpha-tocopherol but not gamma-tocotrienol in mice. Free Radical Biol. Med. 2005, 38 (4), 507-14.

(17) Traber, M. G.; Siddens, L. K.; Leonard, S. W.; Schock, B.; Gohil, K.; Krueger, S. K.; Cross, C. E.; Williams, D. E. alpha-Tocopherol modulates Cyp3a expression, increases gamma-CEHC production, and limits tissue gamma-tocopherol accumulation in mice fed high gamma-tocopherol diets. Free Radical Biol. Med. 2005, 38 (6), 773-85.

(18) Tanabe, M.; Fukushima, T.; Usui, N.; Aoyama, N.; Tsunoda, M.; Imai, K. Intravenous administration of 2,7,8-trimethyl-2-(betacarboxyethyl)-6-hydroxy chroman (gamma-CEHC) to rats and determination of its plasma concentration and urinary sodium excretion. Biomed. Chromatogr. 2004, 18 (9), 727-34.
(19) Morinobu, T.; Yoshikawa, S.; Hamamura, K.; Tamai, H. Measurement of vitamin $\mathrm{E}$ metabolites by high-performance liquid chromatography during high-dose administration of alpha-tocopherol. Eur. J. Clin. Nutr. 2003, 57 (3), 410-4.

(20) Pope, S. A.; Burtin, G. E.; Clayton, P. T.; Madge, D. J.; Muller, D. P. Synthesis and analysis of conjugates of the major vitamin E metabolite, alpha-CEHC. Free Radical Biol. Med. 2002, 33 (6), 807-17.

(21) Ikeda, S.; Tohyama, T.; Yamashita, K. Dietary sesame seed and its lignans inhibit 2,7,8-trimethyl- 2(2'-carboxyethyl)-6-hydroxychroman excretion into urine of rats fed gamma-tocopherol. $J$. Nutr. 2002, 132 (5), 961-6.

(22) Saito, H.; Kiyose, C.; Yoshimura, H.; Ueda, T.; Kondo, K.; Igarashi, O. Gamma-tocotrienol, a vitamin $\mathrm{E}$ homolog, is a natriuretic hormone precursor. J. Lipid Res. 2003, 44 (8), 15305.

(23) Uto, H.; Kiyose, C.; Saito, H.; Ueda, T.; Nakamijra, T.; Igarashi, O.; Kondo, K. Gamma-tocopherol enhances sodium excretion as a natriuretic hormone precursor. J. Nutr. Sci. Vitaminol. (Tokyo) 2004, 50 (4), 277-82.

(24) Uchida, T.; Ichikawa, T.; Abe, C.; Yamashita, K.; Ikeda, S. Dietary sesame seed decreases urinary excretion of alpha- and gammatocopherol metabolites in rats. J. Nutr. Sci. Vitaminol. (Tokyo) 2007, 53 (4), 372-6.

(25) Lodge, J. K.; Ridlington, J.; Leonard, S.; Vaule, H.; Traber, M. G. Alpha- and gamma-tocotrienols are metabolized to carboxyethylhydroxychroman derivatives and excreted in human urine. Lipids 2001, 36 (1), 43-8.

(26) Birringer, M.; Pfluger, P.; Kluth, D.; Landes, N.; Brigelius-Flohe, $\mathrm{R}$. Identities and differences in the metabolism of tocotrienols and tocopherols in HepG2 cells. J. Nutr. 2002, 132 (10), 3113-8.

(27) Sontag, T. J.; Parker, R. S. Cytochrome P450 omega-hydroxylase pathway of tocopherol catabolism. Novel mechanism of regulation of vitamin E status. J. Biol. Chem. 2002, 277 (28), 25290-6.

Received for review August 7, 2008. Revised manuscript received September 30, 2008. Accepted September 30, 2008. The study was financially supported by a grant (NSC 90-2320-B-002-102) from the National Science Council, Taiwan.

JF802459D 